\title{
Síntese e caracterização de nanopartículas de $\mathrm{Y}_{2} \mathrm{O}_{3}$ dopados com Eu e Ti para uso em bioimagens
}

\author{
Ísis Frigeri Manali*, Verônica de Carvalho Teixeira.
}

\section{Resumo}

Neste trabalho, partículas luminescentes de $\mathrm{Y}_{2} \mathrm{O}_{3}$ dopadas com Eu e Ti foram sintetizadas e seu comportamento óptico foi investigado através das técnicas de fotoluminescência (PL) e luminescência óptica excitada por raios $X(X E O L)$. As amostras foram obtidas através da metodologia de sol-gel, assistida por água (Água) e água de coco (ACP) e sua estrutura cristalina foi avaliada através da difração de raios $X(D R X)$. A microscopia eletrônica de varredura foi usada no estudo da morfologia das partículas e revelou que as amostras preparadas através do sol-gel assistido por água de coco apresentam partículas de tamanhos esféricos, regulares e uniformes da ordem de $40 \mathrm{~nm}$ de diâmetro, enquanto aquelas obtidas através do sol-gel assistido por água apresentam formatos irregulares e tamanhos da ordem de centenas de nanômetros. No estudo das propriedades ópticas desses materiais, foi possível observar que o $\mathrm{Eu}^{3+}$ é o principal centro emissor tanto nas amostras dopadas com Eu quanto com EuTi, tendo a transição ${ }^{5} \mathrm{D}_{0} \rightarrow{ }^{7} \mathrm{~F}_{2}$, com máximo $610 \mathrm{~nm}$, como mais intensa. A emissão no vermelho, $610 \mathrm{~nm}$, é particularmente importante para este trabalho, pois é compatível com a janela de transparência de tecidos biológicos, 600 - 900nm, permitindo a aplicação desses materiais, por exemplo, em bioimagens.

\section{Palavras-chave}

Y2O3, Luminescência, Nanomateriais

\section{Introdução}

Nanopartículas luminescentes são de grande interesse ao desenvolvimento de técnicas e métodos para bioimagens. Elas podem ser funcionalizadas e utilizadas como marcadores durante processos biológicos, in situ, ou tratamentos, a exemplo da terapia fotodinâmica ${ }^{1}$.

Algumas características desejáveis a esse tipo de material estão relacionadas ao tamanho de partícula; tempo de decaimento luminescente, da ordem de segundos a horas, para que se possa estudar um ciclo fisiológico específico; e a região em emissão desses materiais, a qual deve acontecer na região entre $600 \mathrm{e}$ $900 \mathrm{~nm}$, em que há uma janela de transparência em tecidos biológicos ${ }^{1}$.

Neste trabalho foi proposta a síntese e o estudo das propriedades estruturais, morfológicas e ópticas de $\mathrm{Y}_{2} \mathrm{O}_{3}$, dopado com $\mathrm{Eu}$ e Ti, com o objetivo de se obter nanopartículas com emissão na região do vermelhoinfravermelho próximo.

\section{Resultados e Discussão}

As amostras dopadas com Eu e EuTi foram sintetizadas através da metodologia de sol-gel, assistida por água (Água) e água de coco (ACP) e calcinadas a $1100^{\circ} \mathrm{C}$. Nas Figuras 1 (a) e (b) é possível observar a morfologia das amostras sintetizadas através do método sol-gel, assistido por água e assistido por água de coco. Nota-se que a água de coco exerce uma função de controle de tamanho de partículas, muito maior que a simples dissolução dos precursores em água.

Os espectros de emissão fotoluminescentes foram gravados sob excitação de $250 \mathrm{~nm}$ e são apresentados na Figura 2. Os resultados indicam que o $\mathrm{Eu}^{3+}$ é responsável pela principal linha de emissão, localizada em $610 \mathrm{~nm}$, na região do vermelho, compatível com a janela de transparência de tecidos biológicos.

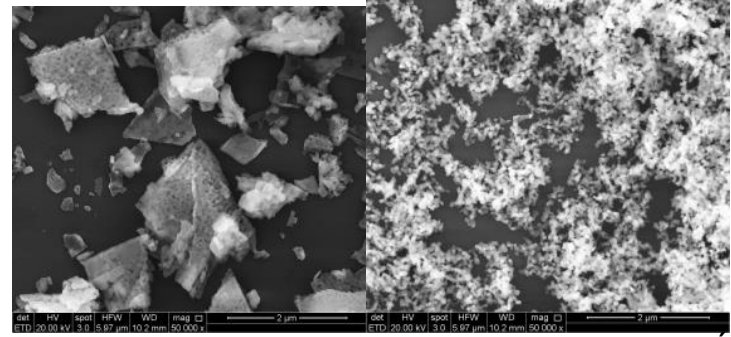

Figura 1. Micrografias das amostras (a) $\mathrm{Y}_{2} \mathrm{O}_{3}$ : Eu (Água) e (a) $\mathrm{Y}_{2} \mathrm{O}_{3}$ : $\mathrm{Eu}(\mathrm{ACP})$

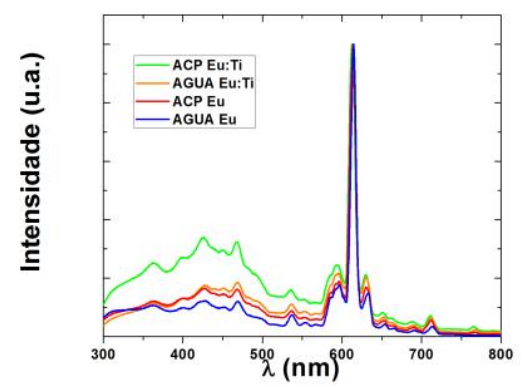

Figura 2. $\mathrm{PL}$ do $\mathrm{Y}_{2} \mathrm{O}_{3}:$ Eu e $\mathrm{Y}_{2} \mathrm{O}_{3}: \mathrm{EuTi}$

\section{Conclusões}

Foram sintetizadas nanopartículas de $\mathrm{Y}_{2} \mathrm{O}_{3}$, com emissão luminescente na região de transparência de tecidos biológicos. Foi observado ainda que a água de coco exerce um controle importante no tamanho e na morfologia das partículas de $\mathrm{Y}_{2} \mathrm{O}_{3}$.

LNLS, CNPEM e CNPq.

\section{Agradecimentos}

${ }^{1}$ ALLISON, R. R.; SIBATA, C. H. Oncologic photodynamic therapy photosensitizers: A clinical review. Photodiagnosis and Photodynamic Therapy, v. 7, n. 2, p. 61-75, 2010. 